\title{
Impact of homogeneous and heterogeneous risk factors on the incidence and prognosis of brain metastases in patients with hepatocellular carcinoma
}

\author{
Xiaoning Lin ${ }^{1,2 \#}$, Pengfei Zhang ${ }^{3 \#}$, Rong Huang ${ }^{4 \#}$, Yanlin Huang ${ }^{1}, J^{2}$ Sun $^{1}$, Huili Zheng ${ }^{5}$, Xinhua Tian ${ }^{1}$, \\ Xiaomin Wang ${ }^{2}$
}

${ }^{1}$ Department of Neurosurgery, ${ }^{2}$ Fujian Provincial Key Laboratory of Chronic Liver Disease and Hepatocellular Carcinoma, Xiamen University Affiliated Zhongshan Hospital, Xiamen, China; ${ }^{3}$ Institute of Molecular Immunology, School of Biotechnology, Southern Medical University, Guangzhou, China; ${ }^{4}$ Department of Child Health, Women and Children's Hospital, Xiamen University, Xiamen, China; ${ }^{5}$ Department of Anesthesiology, Xiamen University Affiliated Zhongshan Hospital, Xiamen, China

Contributions: (I) Conception and design: X Lin, X Tian, X Wang; (II) Administrative support: X Tian, X Wang; (III) Provision of study materials or patients: X Lin; (IV) Collection and assembly of data: X Lin, P Zhang, R Huang; (V) Data analysis and interpretation: X Lin, P Zhang, R Huang; (VI) Manuscript writing: All authors; (VII) Final approval of manuscript: All authors.

\#These authors contributed equally to this work.

Correspondence to: Xiaomin Wang. Fujian Provincial Key Laboratory of Chronic Liver Disease and Hepatocellular Carcinoma, Xiamen University Affiliated Zhongshan Hospital, Xiamen, China. Email: wxm2203@xmu.edu.cn; Xinhua Tian. Department of Neurosurgery, Xiamen University Affiliated Zhongshan Hospital, Xiamen, China. Email: txhmd@163.com.

Background: This study aimed to identify the incidence, risk factors, and survival outcome associated with brain metastases (BM) in hepatocellular carcinoma (HCC) patients using a large-scale population-based cancer registry database.

Methods: Between 2010 and 2016, patients with BM from HCC were included using the Surveillance, Epidemiology, and End Results (SEER) program. The risk and prognostic factors for BM were recognized by multivariate logistic and Cox regression model analysis. The overall survival (OS) and cancer-specific survival (CSS) of HCC patients with BM were assessed using Kaplan-Meier curves with log-rank tests.

Results: A total of 141 (0.33\%) HCC patients detected with BM were included for analysis. Younger age, tumor pathological undifferentiation, no surgery, radiation therapy, no chemotherapy, synchronous bone, or lung metastases were positively associated with BM in the HCC cohort. The median OS and CSS of the BM patients were 3 months, while the corresponding survival time in HCC patients without BM was 13 and 23 months. Black race, tumor pathological undifferentiation, absence of chemotherapy, and concomitant lung metastases were independently associated with the worse survival.

Conclusions: Although the overall prognosis of patients with BM from HCC was extremely poor, a list of homogeneous and heterogeneous risk factors were found to be significantly associated with the occurrence and prognosis of BM in HCC patients. These relevant factors may provide more valuable references for individualized treatment in clinical practice.

Keywords: Hepatocellular carcinoma (HCC); brain metastases (BM); risk factors; prognosis; Surveillance, Epidemiology, and End Results (SEER)

Submitted Apr 22, 2020. Accepted for publication Aug 10, 2020.

doi: 10.21037/apm-20-1012

View this article at: http://dx.doi.org/10.21037/apm-20-1012

^ ORCID: 0000-0002-9645-8475. 


\section{Introduction}

Hepatocellular carcinoma (HCC) is one of the most common cancers worldwide, as well as one of the most common lethal cancers (1). Despite many new advances in HCC treatment, such as novel surgical techniques, transcatheter arterial chemoembolization (TACE), liver transplantation, and radiofrequency ablation, recent reports showed that the 5-year survival rate of HCC is still below $20 \%$, which remains lower than many other cancers $(1,2)$. One of the causes related to high mortality is the extrahepatic metastatic spread of primary carcinoma cells, and the most frequent locations of distant metastases are lungs, bones, lymph nodes and adrenal glands $(3,4)$.

Although the rate of extrahepatic metastases can reach to $18.4 \%$ in newly diagnosed HCC patients, brain metastases $(\mathrm{BM})$ are relatively rare, and it could dramatically worsen patients' prognosis (5). According to previously statistical data, the incidence of BM occurs in about $0.2-2.2 \%$ of HCC patients with a median overall survival (OS) of 16 months (6-11). Results from a published population study showed that the 1-year OS and cancer-specific survival (CSS) was $5.9 \%$ and $6.3 \%$ in patients diagnosed with HCCBM (5). Among all HCCBM patients, most cases are located in supratentorial (11-13), other regions of metastatic HCC to the nervous system include skull $(14,15)$, skull base $(16,17)$, spine $(14,18)$ and sella turcica $(19)$, which lead to various nerve-related events. Recently, with the new drug sorafenib developed and shown to improve the outcome of advanced HCC, some investigators reported that the incidence of $\mathrm{BM}$ increased as more patients survived longer (20-22). However, most previous studies were based on relatively small sample size patients, lacking adequate data to account for HCCBM patients' characteristics and prognosis on a population level. Therefore, it is of importance to identify potentially metastatic risk factors and survival prediction assessment methods of HCCBM for precisely clinical decision-making on a larger scale population.

In the present study, we aimed to assess the newest prevalence, risk factors and prognostic factors of initially diagnosed HCC patients with BM on the basis of the Surveillance, Epidemiology, and End Results (SEER) database. Furthermore, we perform stratified survival variables to analyze their influence on either OS or CSS. We present the following article in accordance with the STROBE reporting checklist (available at http://dx.doi. org/10.21037/apm-20-1012).

\section{Methods}

\section{Cobort population}

Patients' data were obtained from the SEER database, providing clinical incidence, treatment, and survival data on many tumors and covering nearly $36.7 \%$ of the US population according to the 2010 census. We got the database access permission before the research initiation, and he newly SEER*Stat software (version 8.3.6; National Cancer Institute, Bethesda, MD, USA) was used to collect and analyze related data from 2010 to 2016 due to no record of distant metastases before the year 2010. Then, within the SEER database, patients with age $\geq 18$ years diagnosed primary HCC were finally included in our study. The histology/behavior of HCC were limited to "8170/3 hepatocellular carcinoma, not otherwise specified", "8171/3 hepatocellular carcinoma, fibrolamellar", "8172/3 hepatocellular carcinoma, scirrhous", "8173/3 hepatocellular carcinoma, spindle cell variant", " $8174 / 3$ hepatocellular carcinoma, clear cell type" or " $8175 / 3$ hepatocellular carcinoma, pleomorphic type" based on International Classification of Diseases for Oncology-3 (ICD-O-3). Exclusion criteria were as follows: (I) patients whose primary site were not in the liver; (II) patients with unknown BM; (III) patients with unknown survival time. The detailed process of population enrollment was shown in Figure 1, and patients were grouped by the existence of BM. The study conformed to the provisions of the Declaration of Helsinki (as revised in 2013).

The variables including age, sex, marital status, race, insurance status, pathological grade, surgery, radiation, chemotherapy, alpha-fetoprotein (AFP), bone metastases, intrahepatic metastases, lung metastases, BM, vital status, cause-specific death classification and survival time were used in the current study. The race is divided into white, black, others (American Indian/Alaska Native, Asian/Pacific Islander) and unknown. Surgery was classified as no surgery, surgery on primary site (including local treatment and liver resection) and unknown. Radiation was also applied for HCC. AFP level comprised of elevated, normal and unknown. OS and CSS were used to analyze the patients' survival outcomes.

\section{Statistical analysis}

Descriptive statistics were used to summarize demographics, and a chi-square test was performed to compare categorical variables between cases with and without 


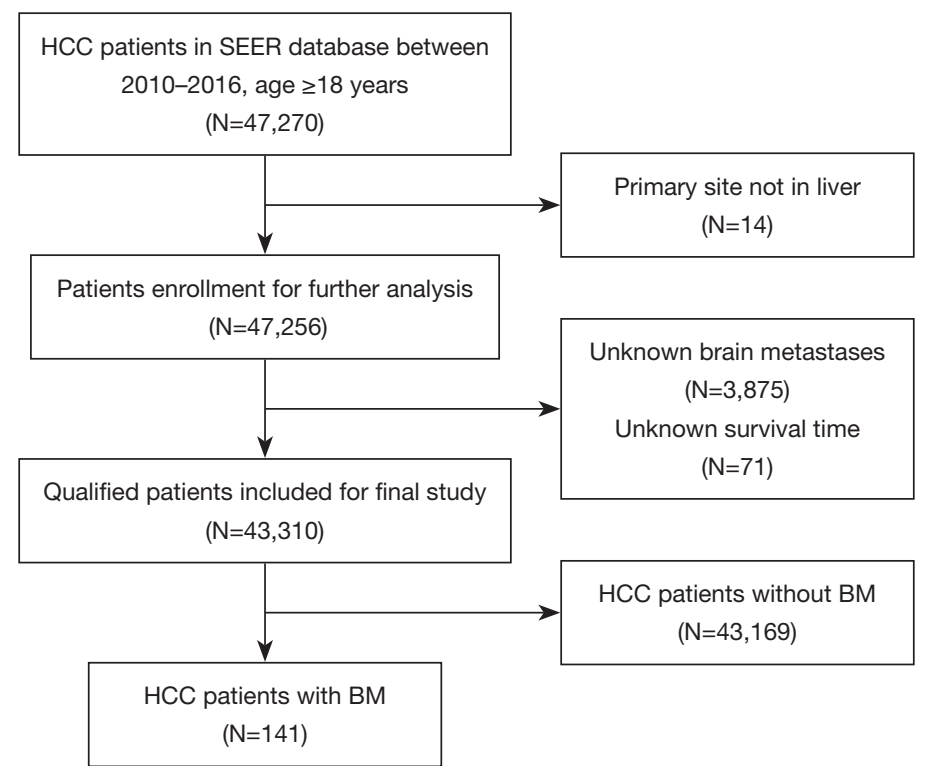

Figure 1 Flowchart of patients enrollment process. HCC, hepatocellular carcinoma; SEER, Surveillance, Epidemiology, and End Results; $\mathrm{BM}$, brain metastases.

$\mathrm{BM}$ as baseline clinical characteristics. The risk factors of HCCBM patients were measured by multivariate logistic regression analysis. The OS and CSS curves were evaluated by using the Kaplan-Meier method with logrank test. The prognostic factors related to OS or CSS were calculated using univariate and multivariable Cox proportional hazards regression models. Those variables with significant differences in univariate Cox regression models were included for further multivariate analysis. All of the statistical analyses were carried out using SPSS software version 23.0 (IBM Corp., Armonk, NY, USA) and statistically significant standard was $\mathrm{P}<0.05$.

\section{Results}

\section{Patients characteristics}

As shown in Figure 1, a total of 43,310 patients with primary HCC from 2010 to 2016 were enrolled in our study, among of which 141 cases $(0.33 \%)$ were presented with BM. The baseline clinical characteristics of primary HCC patients were displayed in Table 1. The median age of the entire cohort at diagnosis of HCC was 64 (range, 18-102) years. No statistical significance was demonstrated in sex, marital status and race $(\mathrm{P}>0.05)$. However, other characteristics, including age, insurance status, pathological grade, surgery, radiation, chemotherapy, AFP, bone metastases, intrahepatic metastases and lung metastases, were shown significant differences between $\mathrm{BM}$ and nonmetastasis patients $(\mathrm{P}<0.05)$. HCCBM patients were found to receive less insurance, surgery and chemotherapy, but more radiation therapy.

\section{Risk factors of HCCBM}

As presented in Table 2, age at the diagnosis less than 50 years $(\mathrm{P}=0.023)$, undifferentiated grade in pathology $(\mathrm{P}=0.016)$, no surgery $(\mathrm{P}=0.004)$, radiation therapy $(\mathrm{P}<0.001)$, no chemotherapy $(\mathrm{P}<0.001)$, bone metastases $(\mathrm{P}<0.001)$ and lung metastases $(\mathrm{P}<0.001)$ were associated with significantly higher risk for BM from HCC according to the results of multivariate logistic regression analysis. Other variables (sex, marital status, race, insurance status, AFP level and intrahepatic metastases) were found not to be significantly relevant with HCCBM $(\mathrm{P}>0.05)$.

\section{Survival analysis}

For the entire cohort study, the median follow-up time was 9 (interquartile range, 2-23) months. While for the HCCBM patients, the median follow-up time was 2 (interquartile range, 0-6) months. The median OS for the HCCBM patients and HCC patients without BM was 3 months [95\% confidence interval (CI): 2.045-3.955] and 
Table 1 Baseline characteristics of the patients with HCC

\begin{tabular}{|c|c|c|c|}
\hline Characteristics & $\begin{array}{l}\text { With BM, } \\
\text { n (\%) }\end{array}$ & $\begin{array}{l}\text { Without BM, } \\
\text { n (\%) }\end{array}$ & $P$ value \\
\hline Age (years) & & & 0.030 \\
\hline$\leq 50$ & $16(11.3)$ & $2,915(6.8)$ & \\
\hline$>50$ & $125(88.7)$ & 40,254 (93.2) & \\
\hline Sex & & & 0.118 \\
\hline Male & $116(82.3)$ & 33,108 (76.7) & \\
\hline Female & $25(17.7)$ & $10,061(23.3)$ & \\
\hline Marital status & & & 0.109 \\
\hline Married & $57(40.4)$ & $21,052(48.8)$ & \\
\hline Unmarried & 77 (54.6) & $19,778(45.8)$ & \\
\hline Unknown & $7(5.0)$ & 2,339 (5.4) & \\
\hline Race & & & 0.467 \\
\hline White & $99(70.2)$ & $29,866(69.2)$ & \\
\hline Black & $24(17.0)$ & $6,041(14.0)$ & \\
\hline Others & $17(12.1)$ & $7,026(16.3)$ & \\
\hline Unknown & $1(0.7)$ & $236(0.5)$ & \\
\hline Insurance status & & & 0.035 \\
\hline Insured & $126(89.4)$ & 40,648 (94.2) & \\
\hline Uninsured & $11(7.8)$ & $1,635(3.8)$ & \\
\hline Unknown & $4(2.8)$ & $886(2.1)$ & \\
\hline Grade & & & 0.013 \\
\hline Well differentiated & $13(9.2)$ & 4,456 (10.3) & \\
\hline $\begin{array}{l}\text { Moderately } \\
\text { differentiated }\end{array}$ & $22(15.6)$ & $6,928(16.0)$ & \\
\hline Poorly differentiated & $12(8.5)$ & $3,106(7.2)$ & \\
\hline Undifferentiated & $4(2.8)$ & $251(0.6)$ & \\
\hline Unknown & $90(63.8)$ & $28,428(65.9)$ & \\
\hline Surgery & & & $<0.001$ \\
\hline No surgery & $135(95.7)$ & $32,586(75.5)$ & \\
\hline Surgery & $6(4.3)$ & $10,470(24.3)$ & \\
\hline Unknown & $0(0.0)$ & $113(0.3)$ & \\
\hline Radiation & & & $<0.001$ \\
\hline No & 78 (55.3) & $39,055(90.5)$ & \\
\hline Yes & $63(44.7)$ & $4,114(9.5)$ & \\
\hline
\end{tabular}

Table 1 (continued)
Table 1 (continued)

\begin{tabular}{lccc}
\hline Characteristics & $\begin{array}{c}\text { With BM, } \\
\mathrm{n}(\%)\end{array}$ & $\begin{array}{c}\text { Without BM, } \\
\mathrm{n}(\%)\end{array}$ & P value \\
\hline Chemotherapy & & & $<0.001$ \\
No & $107(75.9)$ & $24,969(57.8)$ & \\
Yes & $34(24.1)$ & $18,200(42.2)$ & \\
AFP & & & $<0.001$ \\
Normal & $18(12.8)$ & $9,410(21.8)$ & \\
Elevated & $75(53.2)$ & $25,055(58.0)$ & \\
Unknown & $48(34.0)$ & $8,704(20.2)$ & \\
Bone metastases & & & \\
No & $85(60.3)$ & $41,383(95.9)$ & \\
Yes & $51(36.2)$ & $1,721(4.0)$ & \\
Unknown & $5(3.5)$ & $65(0.1)$ & \\
Intrahepatic metastases & & & $<0.001$ \\
No & $122(86.5)$ & $42,546(98.6)$ & \\
Yes & $10(7.1)$ & $478(1.1)$ & \\
Unknown & $9(6.4)$ & $145(0.3)$ & \\
Lung metastases & & & \\
No & $52(36.9)$ & $2,366(5.5)$ & \\
Yes & $4(2.8)$ & $210(0.5)$ & \\
Unknown & & & \\
\hline
\end{tabular}

HCC, hepatocellular carcinoma; BM, brain metastases; AFP, alpha-fetoprotein.

13 months (95\% CI: 12.677-13.323), while the median CSS for the groups of HCCBM patients and HCC patients without BM were 3 months (95\% CI: 2.045-3.966) and 23 months (95\% CI: 22.345-23.655), respectively. Compared to the cohort without BM, the group of HCCBM patients demonstrated significantly shorter OS and CSS with a plummet of the survival curve in the first year $(\mathrm{P}<0.001$, Figure 2). In all variables, pathological grade, chemotherapy and lung metastases had statistically significant difference in the OS curve using the log-rank test $(\mathrm{P}<0.05$, Figure 3). For CSS, race, chemotherapy and lung metastases had significant impact on HCCBM patients $(\mathrm{P}<0.05$, Figure 4$)$.

Based on the univariate and multivariate Cox proportional hazards regression model, black race, undifferentiation, no chemotherapy and lung metastases 
Table 2 Multivariate logistic regression analysis of risk factors of BM from HCC

\begin{tabular}{|c|c|c|c|}
\hline Variables & OR & $95 \% \mathrm{Cl}$ & $P$ value \\
\hline \multicolumn{4}{|l|}{ Age (years) } \\
\hline$\leq 50$ & Reference & - & - \\
\hline$>50$ & 0.530 & $0.307-0.916$ & 0.023 \\
\hline \multicolumn{4}{|l|}{ Sex } \\
\hline Male & Reference & - & - \\
\hline Female & 0.787 & $0.501-1.236$ & 0.299 \\
\hline \multicolumn{4}{|l|}{ Marital status } \\
\hline Married & Reference & - & - \\
\hline Unmarried & 1.335 & $0.928-1.920$ & 0.119 \\
\hline Unknown & NA & NA & NA \\
\hline \multicolumn{4}{|l|}{ Race } \\
\hline White & Reference & - & - \\
\hline Black & 1.022 & $0.643-1.624$ & 0.927 \\
\hline Others & 0.782 & $0.458-1.335$ & 0.367 \\
\hline Unknown & NA & NA & NA \\
\hline \multicolumn{4}{|l|}{ Insurance status } \\
\hline Insured & Reference & - & - \\
\hline Uninsured & 1.702 & $0.894-3.241$ & 0.106 \\
\hline Unknown & NA & NA & NA \\
\hline \multicolumn{4}{|l|}{ Grade } \\
\hline Well differentiated & Reference & - & - \\
\hline $\begin{array}{l}\text { Moderately } \\
\text { differentiated }\end{array}$ & 1.138 & $0.564-2.296$ & 0.719 \\
\hline Poorly differentiated & 0.643 & $0.279-1.481$ & 0.300 \\
\hline Undifferentiated & 4.228 & $1.304-13.713$ & 0.016 \\
\hline Unknown & NA & NA & NA \\
\hline \multicolumn{4}{|l|}{ Surgery } \\
\hline No surgery & Reference & - & - \\
\hline Surgery & 0.283 & $0.121-0.663$ & 0.004 \\
\hline Unknown & NA & NA & NA \\
\hline \multicolumn{4}{|l|}{ Radiation } \\
\hline No & Reference & - & - \\
\hline Yes & 5.861 & $4.017-8.551$ & $<0.001$ \\
\hline
\end{tabular}

Table 2 (continued)
Table 2 (continued)

\begin{tabular}{|c|c|c|c|}
\hline Variables & OR & $95 \% \mathrm{Cl}$ & $P$ value \\
\hline \multicolumn{4}{|c|}{ Chemotherapy } \\
\hline No & Reference & - & - \\
\hline Yes & 0.449 & $0.301-0.670$ & $<0.001$ \\
\hline \multicolumn{4}{|l|}{ AFP } \\
\hline Normal & Reference & - & - \\
\hline Elevated & 1.076 & $0.632-1.833$ & 0.786 \\
\hline Unknown & NA & NA & NA \\
\hline \multicolumn{4}{|c|}{ Bone metastases } \\
\hline No & Reference & - & - \\
\hline Yes & 4.006 & $2.665-6.022$ & $<0.001$ \\
\hline Unknown & NA & NA & NA \\
\hline \multicolumn{4}{|c|}{ Intrahepatic metastases } \\
\hline No & Reference & - & - \\
\hline Yes & 1.421 & $0.701-2.882$ & 0.329 \\
\hline Unknown & NA & NA & NA \\
\hline \multicolumn{4}{|c|}{ Lung metastases } \\
\hline No & Reference & - & - \\
\hline Yes & 5.804 & $3.915-8.603$ & $<0.001$ \\
\hline Unknown & NA & NA & NA \\
\hline
\end{tabular}

All factors with unknown data were removed from the multivariate logistic regression model. BM, brain metastases; HCC, hepatocellular carcinoma; OR, odds ratio; $95 \% \mathrm{Cl}, 95 \%$ confidence interval; AFP, alpha-fetoprotein; NA, not applicable.

were shown to be worse prognosis for HCCBM patients' OS $(\mathrm{P}<0.05$, Table 3). On the aspect of CSS, except for undifferentiated grade, the other three factors above were also demonstrated to cause higher mortality in HCCBM patients $(\mathrm{P}<0.05$, Table 4).

As shown in Figure 5, undifferentiated grade, no chemotherapy and lung metastases were homogeneous risk factors for the incidence and prognosis of BM in HCC. Patients with age less than 50 years, no surgery, radiation therapy and bone metastases were prone to be associated with the development of BM, but not associated with OS and CSS of BM. Black race was significantly related to prognosis of HCCBM patients but could not predict the risk of $\mathrm{BM}$. 

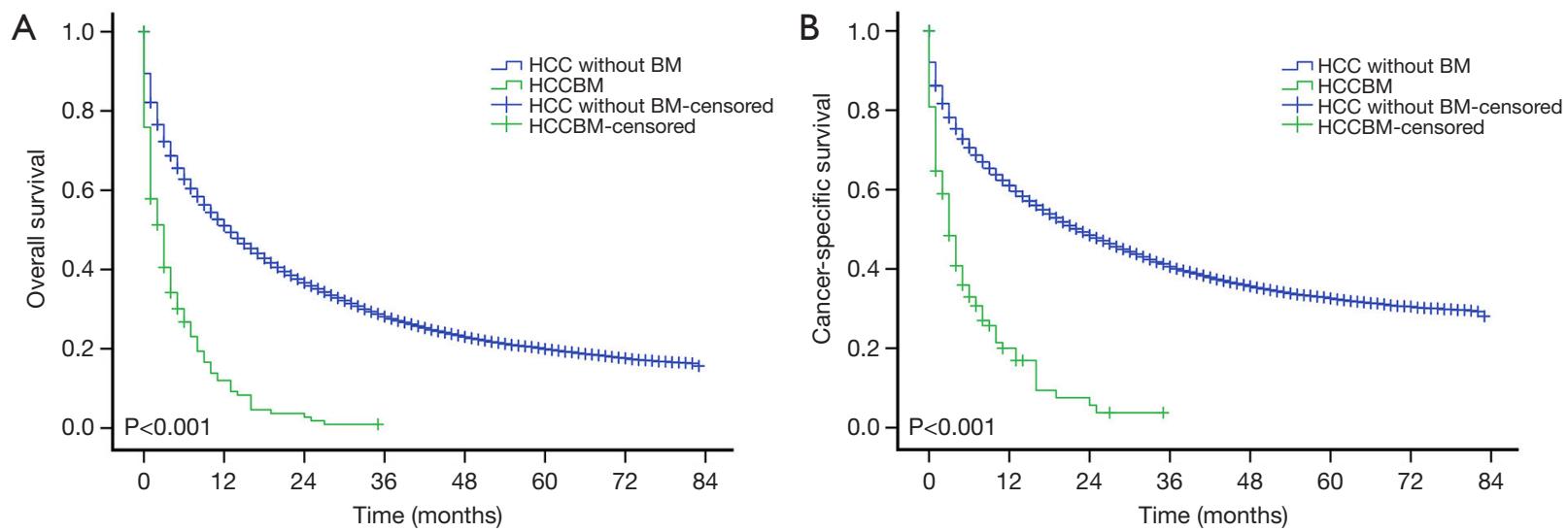

Figure 2 Kaplan-Meier survival curves for OS (A) and CSS (B) in HCC patients with or without BM. OS, overall survival; CSS, cancerspecific survival; BM, brain metastases; HCC, hepatocellular carcinoma.
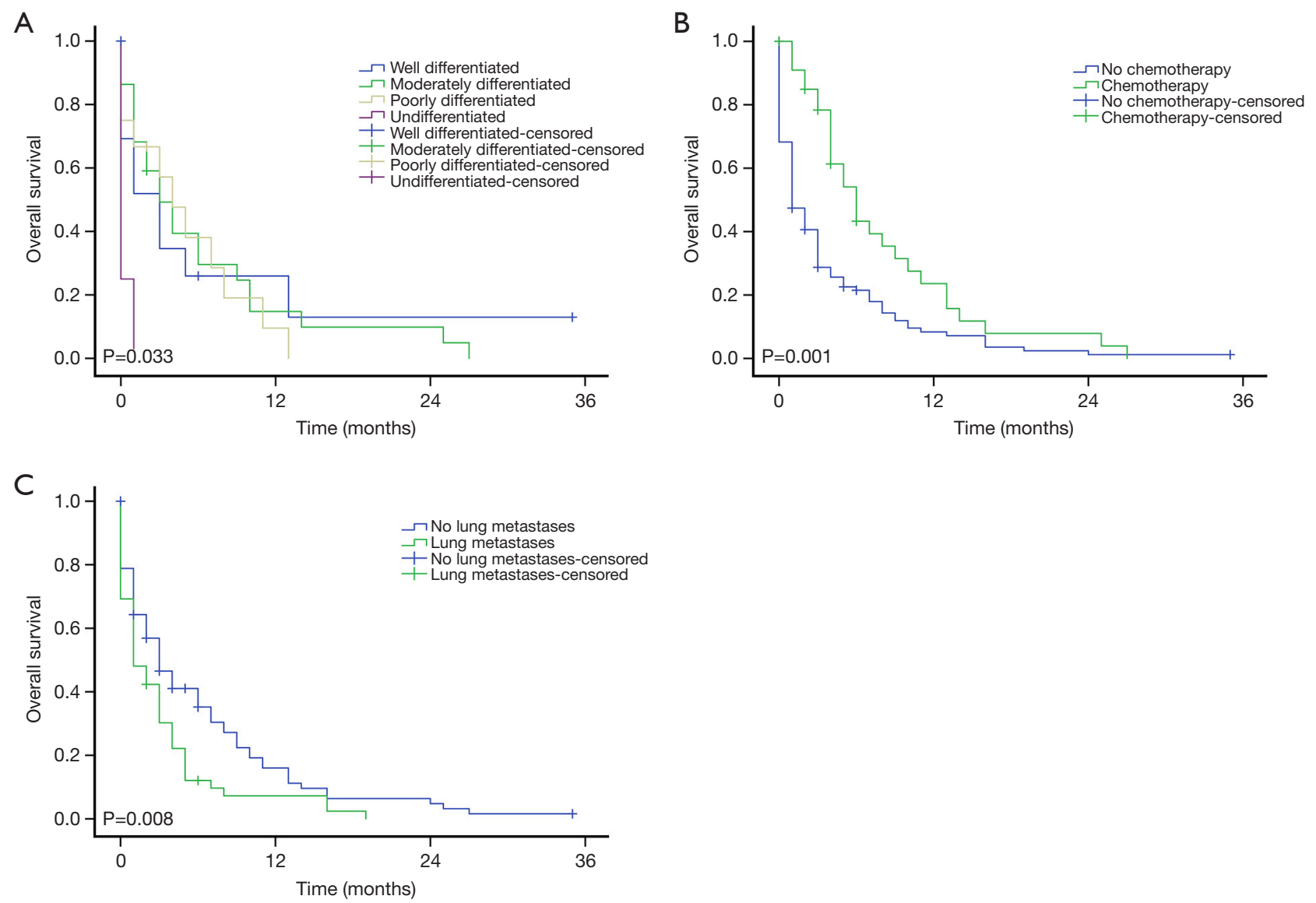

Figure 3 Kaplan-Meier survival curves for OS in patients with BM from HCC. (A) Pathological grade, (B) chemotherapy, (C) lung metastases. OS, overall survival; BM, brain metastases; HCC, hepatocellular carcinoma. 

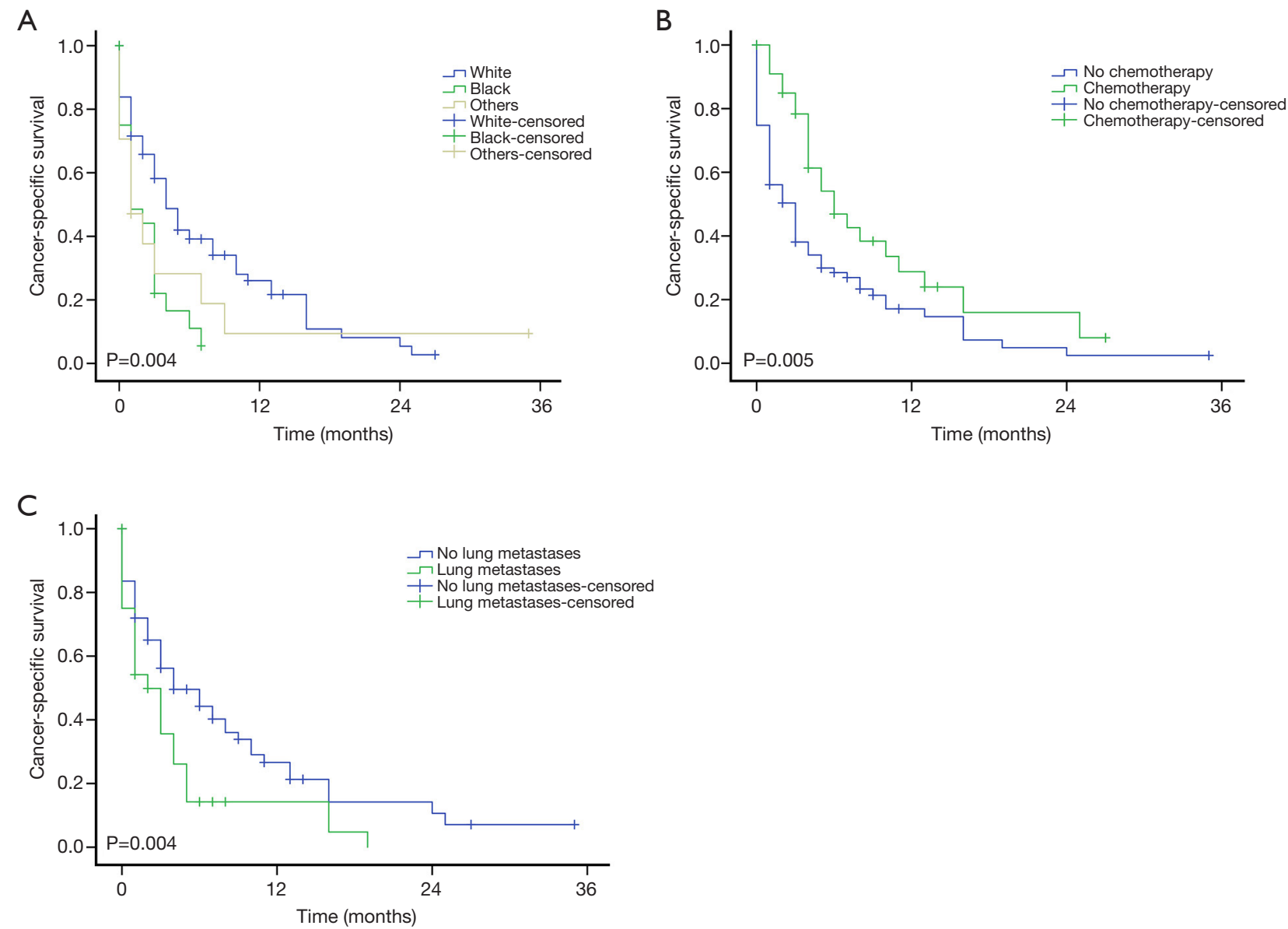

Figure 4 Kaplan-Meier survival curves for CSS in patients with BM from HCC. (A) Race, (B) chemotherapy, (C) lung metastases. CSS, cancer-specific survival; BM, brain metastases; HCC, hepatocellular carcinoma.

\section{Discussion}

As far as we know, this is the biggest study based on population to explore the incidence, risk, and prognostic factors for HCCBM. In comparison with other primary tumor sources, like lung cancer (23) and breast cancer (24), or other extrahepatic metastases places, BM from HCC is relatively uncommon, which may be due to the low affinity of HCC for the central nervous system (CNS) and the rapid disease course and short survival time of patients with HCC, which decreases the probability of BM $(18,25)$. Nam reported that $0.6 \%$ of 13,581 patients with HCC treated in Seoul St. Mary's Hospital and Incheon St. Mary's Hospital were diagnosed with BM between 1995 and 2017 (7). Another study also from South Korea showed that $1.1 \%$ of 10,615 HCC developed BM from 1995 to 2011 (10). The epidemiological result of our study indicated that $0.33 \%$ of patients with $\mathrm{HCC}$ presented with $\mathrm{BM}$, consistent with the prevalence rate in the other cohort research from Chen et al. (6). Nevertheless, according to the investigation carried out by Shao et al., the incidence of BM in advanced HCC patients could reach to $7 \%$ (21). This discrepancy might be due to the differences of enrolled patients: all cases in the work performed by Shao et al. were diagnosed with advanced stages of HCC, whereas cases included in other studies regardless of stage. However, there might be an underestimation in the current study based on the fact that some asymptomatic BM in HCC patients could have been unable to detect.

We then analyzed the risk factors of HCCBM based on multivariate logistic regression. Several risk factors were identified and needed to take notice, including the younger patient ( $\leq 50$ years), tumor pathological undifferentiation, no surgery, radiation therapy, no chemotherapy, synchronal 
Table 3 Univariate and multivariate Cox regression analysis of OS in patients with BM from HCC

\begin{tabular}{|c|c|c|c|c|}
\hline Variables & \multicolumn{2}{|c|}{ Univariate analysis } & \multicolumn{2}{|c|}{ Multivariate analysis } \\
\hline \multicolumn{5}{|l|}{ Age (years) } \\
\hline$\leq 50$ & Reference & & & \\
\hline$>50$ & $1.038(0.604-1.785)$ & 0.892 & & \\
\hline Male & Reference & & & \\
\hline Female & 1.317 (0.848-2.046) & 0.221 & & \\
\hline \multicolumn{5}{|l|}{ Marital status } \\
\hline Married & Reference & & & \\
\hline \multicolumn{5}{|l|}{ Race } \\
\hline White & Reference & & Reference & \\
\hline Black & 1.669 (1.031-2.701) & 0.037 & 1.703 (1.037-2.799) & 0.036 \\
\hline Others & $1.285(0.737-2.240)$ & 0.377 & $1.366(0.759-2.459)$ & 0.299 \\
\hline Unknown & NA & NA & NA & NA \\
\hline \multicolumn{5}{|l|}{ Insurance status } \\
\hline Insured & Reference & & & \\
\hline Uninsured & $0.920(0.465-1.817)$ & 0.810 & & \\
\hline Undifferentiated & $4.323(1.315-14.215)$ & 0.016 & $6.084(1.756-21.086)$ & 0.004 \\
\hline Unknown & NA & NA & NA & NA \\
\hline \multicolumn{5}{|l|}{ Surgery } \\
\hline No surgery & Reference & & & \\
\hline Surgery & $0.509(0.206-1.257)$ & 0.143 & & \\
\hline \multicolumn{5}{|l|}{ Radiation } \\
\hline No & Reference & & & \\
\hline Yes & $0.809(0.568-1.151)$ & 0.239 & & \\
\hline \multicolumn{5}{|l|}{ Chemotherapy } \\
\hline No & Reference & & Reference & \\
\hline Yes & $0.523(0.342-0.800)$ & 0.003 & $0.572(0.365-0.897)$ & 0.015 \\
\hline
\end{tabular}

Table 3 (continued) 
Table 3 (continued)

\begin{tabular}{|c|c|c|c|c|}
\hline Variables & \multicolumn{2}{|c|}{ Univariate analysis } & \multicolumn{2}{|c|}{ Multivariate analysis } \\
\hline \multicolumn{5}{|l|}{ AFP } \\
\hline Normal & Reference & & & \\
\hline Elevated & 1.189 (0.695-2.034) & 0.528 & & \\
\hline \multicolumn{5}{|c|}{ Bone metastases } \\
\hline No & Reference & & & \\
\hline Yes & $0.758(0.522-1.102)$ & 0.147 & & \\
\hline Unknown & NA & NA & & \\
\hline Yes & $1.170(0.609-2.244)$ & 0.638 & & \\
\hline Unknown & NA & NA & & \\
\hline \multicolumn{5}{|c|}{ Lung metastases } \\
\hline No & Reference & & Reference & \\
\hline Yes & $1.562(1.081-2.257)$ & 0.017 & $1.566(1.073-2.228)$ & 0.020 \\
\hline Unknown & NA & NA & NA & NA \\
\hline
\end{tabular}

All factors with unknown data were removed from the Cox and Kaplan-Meier model. OS, overall survival; BM, brain metastases; HCC, hepatocellular carcinoma; HR, hazard ratio; $95 \%$ CI, 95\% confidence interval; AFP, alpha-fetoprotein; NA, not applicable.

bone or lung metastases. These significant predictors could be helpful for clinical decision-making on the potential of BM when encountering HCC patients with the abovementioned characteristics. For the radiation-treated patients or younger patients with a high frequency of BM, the reasons are not quite clear. However, it was also found that younger patients had a higher incidence of lung metastases in previous reports, which might be due to the potentially longer survival time and then more chance to develop metastases. Previous studies also indicated that HCCBM patients had a high proportion of synchronous extra-cranial metastases, with lung (32.6-94.8\%) and bone (14.7-40.7\%) ranking the first two common sites $(7-10,18,22,26)$. An investigation worked by Seinfeld et al. found that some BM could be secondary to lung deposits in HCC patients (11). Therefore, magnetic resonance imaging (MRI), or at least computed tomography (CT) should be considered to be used to timely detect BM for these HCC patients with high risk factors, although there is still no study showed whether routing screening could prolong OS.
Patients with HCCBM usually have an extremely poor prognosis and quality of life. In our study, compared to the HCC patients without BM, the median OS and CSS of HCCBM patients had significantly shortened to 3 months, in line with the previous studies with a median OS of $1-$ 6 months (6-11). Kim reported a parallelly median OS with 3 months in 95 HCCBM patients between January 2000 and December 2011 (26). Yamakawa also reported a similarly median OS with 3.6 months in 15 Japanese patients from January 2003 to December 2012 (27). Another earlier research based on SEER showed that the median OS of 97 HCCBM patients was 2.4 months (6). Our study further demonstrated that HCC patients having BM with black race, tumor pathological undifferentiation, absence of chemotherapy, or presence of lung metastases significantly contributed to an unfavorable prognosis. According to the above-recognized factors, clinicians could approximately evaluate the survival and prognosis of HCCBM patients. Therefore, tumor undifferentiated grade, no chemotherapy and concomitant lung metastases were crucial factors for 
Table 4 Univariate and multivariate Cox regression analysis of CSS in patients with BM from HCC

\begin{tabular}{|c|c|c|c|c|}
\hline Variables & \multicolumn{2}{|c|}{ Univariate analysis } & \multicolumn{2}{|c|}{ Multivariate analysis } \\
\hline \multicolumn{5}{|l|}{ Age (years) } \\
\hline$\leq 50$ & Reference & & & \\
\hline$>50$ & $0.941(0.524-1.690)$ & 0.839 & & \\
\hline Male & Reference & & & \\
\hline Female & $1.466(0.912-2.357)$ & 0.115 & & \\
\hline \multicolumn{5}{|l|}{ Marital status } \\
\hline Married & Reference & & & \\
\hline \multicolumn{5}{|l|}{ Race } \\
\hline White & Reference & & Reference & \\
\hline Black & $2.088(1.257-3.466)$ & 0.004 & 2.053 (1.230-3.429) & 0.006 \\
\hline Others & $1.526(0.837-2.782)$ & 0.168 & $1.497(0.808-2.771)$ & 0.200 \\
\hline Unknown & NA & NA & NA & NA \\
\hline \multicolumn{5}{|l|}{ Insurance status } \\
\hline Insured & Reference & & & \\
\hline Uninsured & $1.159(0.582-2.308)$ & 0.674 & & \\
\hline \multicolumn{5}{|l|}{ Grade } \\
\hline Undifferentiated & $3.890(1.003-15.092)$ & 0.050 & & \\
\hline Unknown & NA & NA & & \\
\hline \multicolumn{5}{|l|}{ Surgery } \\
\hline No surgery & Reference & & & \\
\hline Surgery & $0.632(0.254-1.573)$ & 0.324 & & \\
\hline \multicolumn{5}{|l|}{ Radiation } \\
\hline No & Reference & & & \\
\hline Yes & $0.903(0.610-1.336)$ & 0.609 & & \\
\hline \multicolumn{5}{|l|}{ Chemotherapy } \\
\hline No & Reference & & Reference & \\
\hline Yes & $0.541(0.338-0.865)$ & 0.010 & $0.590(0.368-0.948)$ & 0.029 \\
\hline
\end{tabular}

Table 4 (continued) 
Table 4 (continued)

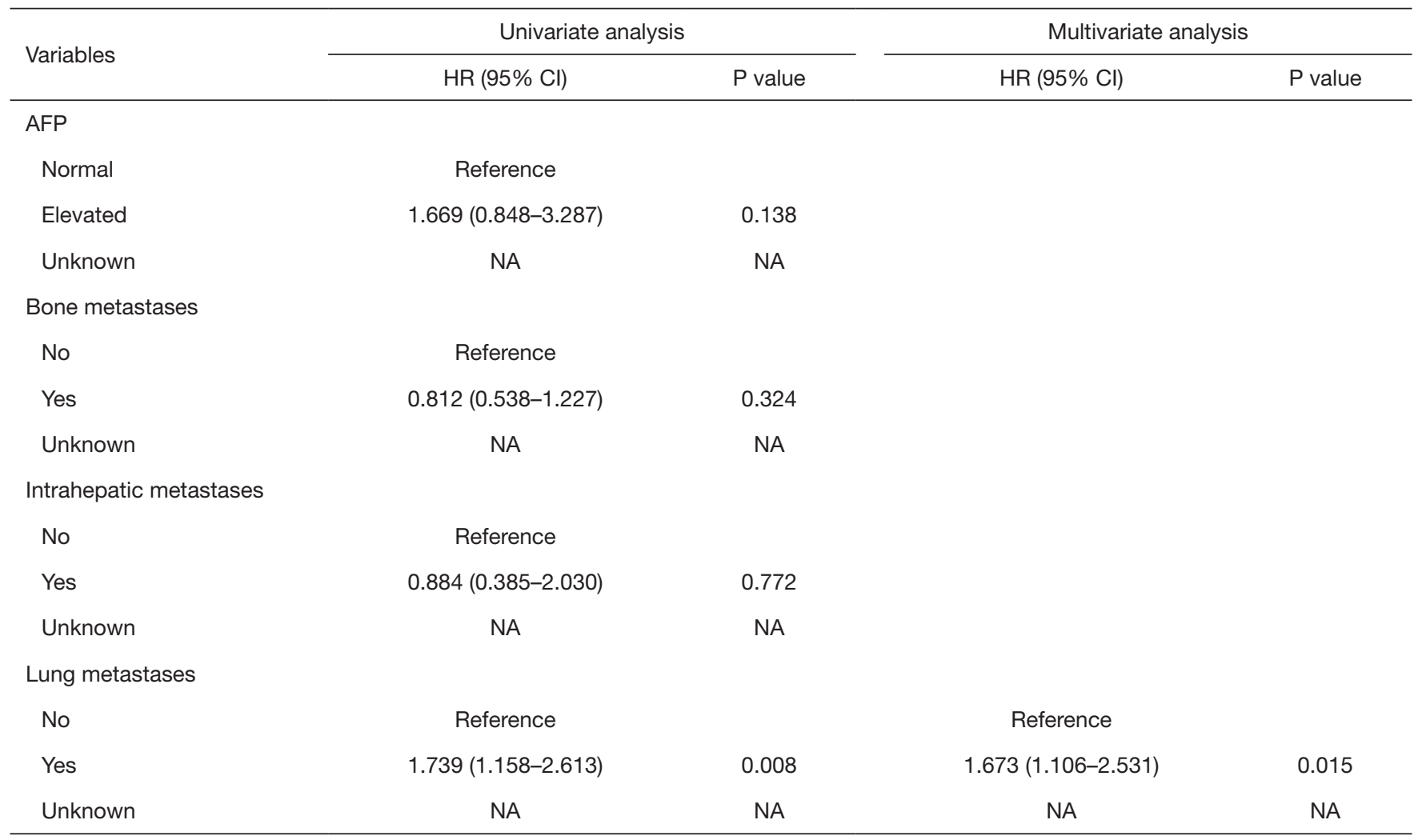

All factors with unknown data were removed from the Cox and Kaplan-Meier model. CSS, cancer-specific survival; BM, brain metastases; HCC, hepatocellular carcinoma; HR, hazard ratio; $95 \% \mathrm{Cl}, 95 \%$ confidence interval; AFP, alpha-fetoprotein; NA, not applicable.

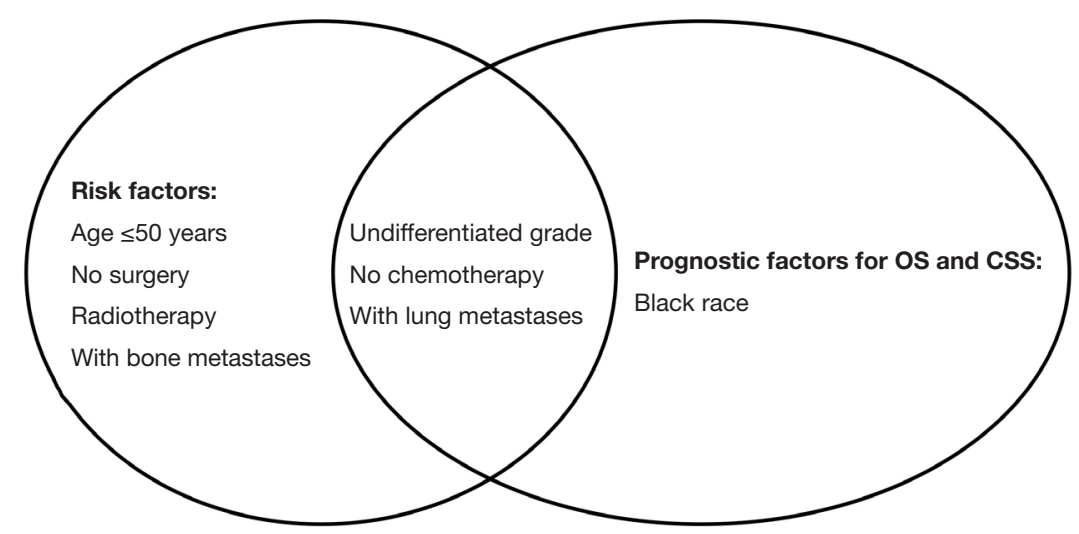

Figure 5 The homogeneous and heterogeneous risk factors for the incidence and prognosis of BM patients in HCC. The left circle was the risk factors for the development of BM. The right circle was the risk factors for the prognosis of BM patients. The intersection of two circles meant the homogeneous risk factors. BM, brain metastases; HCC, hepatocellular carcinoma; OS, overall survival; CSS, cancer-specific survival. 
both predictive risk and prognosis.

Although different races had no impact on the risk for BM in HCC patients, the OS and CSS in the black population appeared significantly worse than white people. Jones found that survival among Blacks is the shortest after HCC diagnosis in a diverse sample of patients due to the possibility of lacking insurance or enough financial support, which could be barriers to many interventions, leading to receiving treatment at a more advanced tumor stage (28). Other investigations also revealed a similar result of shorter OS in black patients with HCC $(29,30)$. Undoubtedly, the exact mechanism underlying this phenomenon still needs to be explored. AFP, an indicator that reflects the tumor burden, usually indicated significant for survival in the previous study $(9,26)$; however, there was no difference in our research, which might be caused by more than onethird of unknown cases in this data set.

Up to now, there are no guidelines on diagnosis and therapeutic strategy for HCCBM, owing to the rarity and poor prognosis of these patients. However, compared to metastatic tumor control, it is widely acknowledged that better-control of primary HCC lesion contributes to longer survival time because patients' survival mainly relies on the condition of the liver function determined by intrahepatic tumor burden $(7,31,32)$. Our study showed that surgery for HCC could decrease the risk of BM, but have no significant influence on patients' prognosis. These may be due to the fact that the majority of patients did not receive surgery in this study, which most likely led to the difference compared with the reported data. Besides, it was evident that HCCBM patients undergoing chemotherapy survived longer in the present research. It is generally recognized that conventional chemotherapeutic drugs are challenging to access the brain due to the blood-brain barrier (BBB) and have no effect on improving OS for any subset of HCC $(2,33,34)$. Consequently, we speculate that the prolonged survival caused by chemotherapy might be attributed to greater opportunity for patients to receive surgery or stereotactic radiosurgery (SRS) on BM, which was not provided in the SEER database. Further studies on how to improve the survival of HCCBM patients are still warranted in the future.

We recognize that this study has several important limitations. First, there is an inherent bias in any retrospective study that is inevitable. Second, the asymptomatic cases of HCCBM are not recorded in the SEER database, which may lead to an underestimation of the real incidence of BM. Third, details on the treatment modalities (i.e., surgery, radiotherapy, chemotherapy or immunotherapy) for primary tumor and metastatic brain lesions are not available in the SEER database, crucial for analysis. Finally, several critical prognostic factors, including performance status, systemic disease status, Child-Pugh class, etiology (hepatitis B, C, or alcohol), or the number of metastatic lesions, are unable to obtain from the SEER database. Therefore, it is still critical to confirm the findings of our study by prospective validation.

In conclusion, through the above analysis, the incidence of BM in HCC patients is $0.33 \%$. Despite the limitations, the present study provided the homogeneous and heterogeneous risk factors for HCCBM incidence and prognosis based on the SEER database. These factors could be potentially used as references for individualized treatment in clinical decision-making.

\section{Acknowledgments}

Funding: This research was funded by Medical and Health Key project of Xiamen (grant number: 3502Z20191106), Joint Research Project of Science and Technology Bureau and Health Commission of Xiamen (grant number: 3502Z20179046), Joint Fund Science and Technology Department and Health Commission of Fujian Province (grant number: 2019J01562), and President Fund of Xiamen University (grant number: 20720190138).

\section{Footnote}

Reporting Checklist: The authors have completed the STROBE statement reporting checklist. Available at http:// dx.doi.org/10.21037/apm-20-1012

Data Sharing Statement: Available at http://dx.doi. org/10.21037/apm-20-1012

Conflicts of Interest: All authors have completed the ICMJE uniform disclosure form (available at http://dx.doi. org/10.21037/apm-20-1012). The authors have no conflicts of interest to declare.

Ethical Statement: The authors are accountable for all aspects of the work in ensuring that questions related to the accuracy or integrity of any part of the work are appropriately investigated and resolved. The study conformed to the provisions of the Declaration of Helsinki (as revised in 2013). The approval process of the 
Institutional Review Board was waived because of the deidentified information of the patients included in the SEER.

Open Access Statement: This is an Open Access article distributed in accordance with the Creative Commons Attribution-NonCommercial-NoDerivs 4.0 International License (CC BY-NC-ND 4.0), which permits the noncommercial replication and distribution of the article with the strict proviso that no changes or edits are made and the original work is properly cited (including links to both the formal publication through the relevant DOI and the license). See: https://creativecommons.org/licenses/by-nc-nd/4.0/.

\section{References}

1. Bray F, Ferlay J, Soerjomataram I, et al. Global cancer statistics 2018: GLOBOCAN estimates of incidence and mortality worldwide for 36 cancers in 185 countries. CA Cancer J Clin 2018;68:394-424.

2. Villanueva A. Hepatocellular carcinoma. N Engl J Med 2019;380:1450-62.

3. Uka K, Aikata H, Takaki S, et al. Clinical features and prognosis of patients with extrahepatic metastases from hepatocellular carcinoma. World J Gastroenterol 2007;13:414-20.

4. Chen D, Li Z, Song Q, et al. Clinicopathological features and differential diagnosis of hepatocellular carcinoma in extrahepatic metastases. Medicine (Baltimore) 2018;97:e13356.

5. $\mathrm{Wu} W, \mathrm{He} X$, Andayani D, et al. Pattern of distant extrahepatic metastases in primary liver cancer: a SEER based study. J Cancer 2017;8:2312-8.

6. Chen QF, Huang T, Shen L, et al. Predictive value of a nomogram for hepatocellular carcinoma with brain metastasis at initial diagnosis: a population-based study. PLoS One 2019;14:e0209293.

7. Nam HC, Sung PS, Song DS, et al. Control of intracranial disease is associated with improved survival in patients with brain metastasis from hepatocellular carcinoma. Int J Clin Oncol 2019;24:666-76.

8. Okuda T, Hayashi N, Takahashi M, et al. Clinical outcomes of brain metastases from hepatocellular carcinoma: a multicenter retrospective study and a literature review. Int J Clin Oncol 2018;23:1095-100.

9. Park Y, Kim KS, Kim K, et al. Nomogram prediction of survival in patients with brain metastases from hepatocellular carcinoma treated with whole-brain radiotherapy: a multicenter retrospective study. J
Neurooncol 2015;125:377-83.

10. Lim S, Lee S, Lim JY, et al. Hepatocellular carcinoma specific graded prognostic assessment can predict outcomes for patients with brain metastases from hepatocellular carcinoma. J Neurooncol 2014;120:199-207.

11. Seinfeld J, Wagner AS, Kleinschmidt-DeMasters BK. Brain metastases from hepatocellular carcinoma in US patients. J Neurooncol 2006;76:93-8.

12. Chang L, Chen YL, Kao MC. Intracranial metastasis of hepatocellular carcinoma: review of 45 cases. Surg Neurol 2004;62:172-7.

13. Hammond WJ, Lalazar G, Saltsman JA, et al. Intracranial metastasis in fibrolamellar hepatocellular carcinoma. Pediatr Blood Cancer 2018;65:10.

14. Uei H, Tokuhashi Y, Maseda M, et al. Surgical management of coincidental metastases to upper cervical spine and skull from hepatocellular carcinoma: a case report. J Int Med Res 2018;46:4852-9.

15. Ferraz VR, Vitorino-Araujo JL, Sementilli L, et al. Lesion in scalp and skull as the first manifestation of hepatocellular carcinoma. Case Rep Neurol Med 2016;2016:2897048.

16. Woo KM, Kim BC, Cho KT, et al. Spontaneous epidural hematoma from skull base metastasis of hepatocellular carcinoma. J Korean Neurosurg Soc 2010;47:461-3.

17. Carey RA, Nathaniel SD, Das S, et al. Cavernous sinus syndrome due to skull base metastasis: a rare presentation of hepatocellular carcinoma. Neurol India 2015;63:437-9.

18. Hsiao SY, Chen SF, Chang CC, et al. Central nervous system involvement in hepatocellular carcinoma: clinical characteristics and comparison of intracranial and spinal metastatic groups. J Clin Neurosci 2011;18:364-8.

19. Chen SF, Tsai NW, Lui CC, et al. Hepatocellular carcinoma presenting as nervous system involvement. Eur J Neurol 2007;14:408-12.

20. Llovet JM, Ricci S, Mazzaferro V, et al. Sorafenib in advanced hepatocellular carcinoma. N Engl J Med 2008;359:378-90.

21. Shao YY, Lu LC, Cheng AL, et al. Increasing incidence of brain metastasis in patients with advanced hepatocellular carcinoma in the era of antiangiogenic targeted therapy. Oncologist 2011;16:82-6.

22. Jiang XB, Ke C, Zhang GH, et al. Brain metastases from hepatocellular carcinoma: clinical features and prognostic factors. BMC Cancer 2012;12:49.

23. Kakusa B, Han S, Aggarwal S, et al. Clinical factors associated with mortality within three months after radiosurgery of asymptomatic brain metastases from nonsmall cell lung cancer. J Neurooncol 2018;140:705-15. 
24. Mix M, Elmarzouky R, O'Connor T, et al. Clinical outcomes in patients with brain metastases from breast cancer treated with single-session radiosurgery or whole brain radiotherapy. J Neurosurg 2016;125:26-30.

25. Kim M, Na DL, Park SH, et al. Nervous system involvement by metastatic hepatocellular carcinoma. J Neurooncol 1998;36:85-90.

26. Kim KS, Kim K, Chie EK, et al. Prognostic stratification of brain metastases from hepatocellular carcinoma. J Neurooncol 2014;120:209-14.

27. Yamakawa Y, Moriguchi M, Aramaki T, et al. Brain metastasis from hepatocellular carcinoma: The impact of radiotherapy on control of intracranial hemorrhage. Hepatol Res 2015;45:1071-5.

28. Jones PD, Diaz C, Wang D, et al. The impact of race on survival after hepatocellular carcinoma in a diverse American population. Dig Dis Sci 2018;63:515-28.

29. Hoehn RS, Hanseman DJ, Wima K, et al. Does race affect management and survival in hepatocellular carcinoma in the United States? Surgery 2015;158:1244-51.

Cite this article as: Lin X, Zhang $\mathrm{P}$, Huang $\mathrm{R}$, Huang $\mathrm{Y}$, Sun J, Zheng H, Tian X, Wang X. Impact of homogeneous and heterogeneous risk factors on the incidence and prognosis of brain metastases in patients with hepatocellular carcinoma. Ann Palliat Med 2020;9(5):2654-2667. doi: 10.21037/apm-20-1012
30. Artinyan A, Mailey B, Sanchez-Luege N, et al. Race, ethnicity, and socioeconomic status influence the survival of patients with hepatocellular carcinoma in the United States. Cancer 2010;116:1367-77.

31. Uchino K, Tateishi R, Shiina S, et al. Hepatocellular carcinoma with extrahepatic metastasis: clinical features and prognostic factors. Cancer 2011;117:4475-83.

32. Jung SM, Jang JW, You CR, et al. Role of intrahepatic tumor control in the prognosis of patients with hepatocellular carcinoma and extrahepatic metastases. J Gastroenterol Hepatol 2012;27:684-9.

33. da Fonseca LG, Marta GN, Braghiroli M, et al. Safety and efficacy of cytotoxic chemotherapy in hepatocellular carcinoma after first-line treatment with sorafenib. BMC Cancer 2018;18:1250.

34. Thomas MB, O'Beirne JP, Furuse J, et al. Systemic therapy for hepatocellular carcinoma: cytotoxic chemotherapy, targeted therapy and immunotherapy. Ann Surg Oncol 2008;15:1008-14. 